\title{
Threshold Cointegration Approach for Assessing the Impact of US Economic Policy Uncertainty on Monetary Policy Decision of African Countries
}

\author{
Prince Mensah Osei* iD, Anokye M. Adam**
}

\begin{abstract}
This study uses threshold cointegration technique to ascertain the relationship between United States (US) economic policy uncertainty (EPU) and monetary policy rate (MPR) of each of the four African countries, namely Egypt, Ghana, Namibia and South Africa using monthly data from March 1998 to April 2020. The impact of US EPU on MPR of each country is assessed by examining the linear cointegration, asymmetric cointegration and causal relationships in the frequency domain between the US EPU and MPR of each African country. The findings provide evidence of long-run threshold cointegration and the adjustment mechanisms towards long-run equilibrium are asymmetric in the short run for the MPR models for Ghana, Namibia and South Africa in the M-TAR specification except for Egypt's MPR model which does not provide evidence of asymmetric adjustment towards the equilibrium position. The bivariate analysis performed in the spectral frequency domain suggests unidirectional causality between US EPU and MPR of each country and that, the US EPU influences the MPR of each country in the long run. The findings provide important guidelines to monetary policy reviewers to take policy stance that would stimulate economic growth amid US policy uncertainties.
\end{abstract}

Keywords: monetary policy rate; economic policy uncertainty; threshold cointegration; asymmetric adjustment; Granger causality.

JEL classification: C58; G0.

\section{INTRODUCTION}

Global adverse events such as the 1997-98 Asian financial crisis, September 11 terrorist attack in the United States (US), the Global Financial Crises (GFC), European sovereign debt crises, trade wars, etc., usually fuel economic policy uncertainty (EPU) in both advanced and developing economies. For example, the 2008-09 GFC was seen to have huge adverse shocks on monetary, financial, and economic conditions across the globe (Belke, Gros, \& Thomas, 2017). Globalisation has made a seemingly unrelated event in one country to transmit to

\footnotetext{
"Ghana Communication Technology University-Kumasi Campus, Ghana; e-mail: princeoseiuk@yahoo.co.uk (corresponding author).

*** School of Business, University of Cape Coast, Ghana; e-mail: aadam@ucc.edu.gh.
} 
another country where the effects of these shocks are persistent and can be reinforced by other shocks. It has been established that even between different types of uncertainties are spillovers and according to Gabauer and Gupta (2020), financial uncertainty transmits the shocks that drive economic and real estate uncertainty. When economic policymakers around the globe, especially in the emerging and the developing economies, are uncertain about the economic policies of a central country, for example, the US, monetary policy decision (MPD) is usually affected especially when the country's monetary policy goal is inflation targeting. Because there is high uncertainty about exchange rate movement, crude oil prices, interest rates, output growth return, etc. during periods of rising EPU in both global and local economies where these factors account for the underlying price pressures most especially in emerging economies, economic policymakers usually adopt a monetary policy stance that would curtail the expected rising inflation.

The goal of MPD of most of the African countries is inflation targeting and the countries that fall in this category usually adjust their monetary policy rate (MPR) to bring back confidence to the economy, amid unfavourable global events. The US is known to be the largest economy in the world and plays a very vital role in the world's economy. For this reason, any event in the US that creates uncertainty in the minds of economic watchers both local and global can lead to the global economic downturn, as this manifested in the 2008 and 2009 GFC. Given this, turbulence and turmoil in the US economy and its financial markets could be substantially transferred to other countries either directly or indirectly (Zhang, Lei, Ji, \& Kutan, 2019). African economies that are regarded as small open economies are mostly at the receiving end of rising US EPU and the need for African economic policymakers to react positively to potential EPU spillovers from the US would be paramount in averting any negative impact of the spillovers to their economies. Targeting inflation as a monetary policy goal sets the platform for countries that focus on controlling inflation amid rising or declining EPU to adjust MPR to reflect the dynamics of the time. It is worth noting that EPU spillovers from the US could create uncertainty around exchange rate movement, growth in economic activity and output gap, unemployment rate and interest rate movement which underpin the underlying price pressures in emerging market economies where African countries are not excepted. Therefore, examining the nexus of US EPU and MPR of African countries that are proxied by MPR used to control rising inflation for sustaining economic growth and job creation in the African continent is quite significant and timely.

In this study, we examine the impact of US EPU on MPD of five African countries including Egypt, South Africa, Namibia and Ghana where their MPDs are proxied by their MPRs using threshold cointegration technique. Our choice of these African countries is dependent on the fact that these countries' MPD objectives are inflation targeting which can easily be influenced by rising economic uncertainty either from an internal or external source. Because the US is currently the central country (Gupta, Lau, Nel, \& Sheng, 2020), its economic and financial uncertainty does not only affect the advanced economies that are seen to be highly integrated with the US economy, but emerging market economies are also impacted through trade and financial channels (IMF, 2013). Hence, examining US EPU's impact on emerging economies such as the selected African countries is highly justified. As it is obvious that the magnitude of EPU is dependent on the intensity of the global economic and financial crises and since all global adverse events occur with different intensity and diverse effects on the world's economy, using the traditional linear techniques to examine relationships may not be able to adequately capture the complex nonlinear characteristics of EPU dynamics. In addition, because 
one of the key objectives for the study is to observe how MPR asymmetrically adjusts to shortrun divergence in EPU in the long-run equilibrium, choosing the threshold cointegration over the traditional linear cointegration will help to unearth the nonlinear long-run relationship between the MPR of each African country and US EPU.

Since the incidence of the GFC, a chunk of the studies on uncertainty have focused on quantifying the impact of uncertainty on the macroeconomy based on different forms of econometric models - see Castelnuovo, Lim, and Pellegrino (2017); Gupta, Ma, Risse, and Wohar (2018) and the majority of these studies dealt with US uncertainty impact on its macroeconomic variables. However, some studies have focused on US uncertainty spillovers on economies like the Euro area, Japan, Sweden, UK and other groups of emerging countries - see Colombo (2013); Jones and Olson (2015); Choi (2018); Kang, Ratti, and Vespignani (2019). Studies that examine US EPU shock transmission to the international economy such as BRICS, G7 and emerging market economies, focused on the impact of US EPU on stock market returns - see Sum (2012); Mensi, Hammoudeh, Reboredo, and Nguyen (2014); Dakhlaoui and Aloui (2016); Li, Li, Yuan, and Yu (2020). Even though there has not been specific studies in our view dedicated to examining US EPU dynamics in relation to the dynamics of MPD of African countries, few studies have investigated the impact of US monetary policy decision uncertainty on some African countries most especially South Africa and few others see - Bowman, Juan, and Sapriza (2014); Kalu, Okoyeuzu, Ukemenam, and Ujunwa (2020); Kabundi, Loate, and Viegi (2020)). It is against this backdrop that we seek to investigate the impact of US EPU on MPD of African countries since to the best of our knowledge, our study is first to contribute to the existing literature by unravelling the long-run equilibrium relationship if any, between US EPU and MPD of African countries proxied by MPR.

Employing threshold cointegration technique as a methodological tool to establish the long-run nonlinear equilibrium relationships between the MPD of African countries proxied by their MPRs and the US EPU reveal the existence of asymmetric adjustment of the MPRs of Ghana, Namibia and South Africa to the divergence of US EPU from the long-run equilibrium and that the speed of adjustment for negative deviations is more rapid than the speed of adjustment for positive deviations. However, the null hypothesis of symmetric adjustment could not be rejected for Egypt's MPR model. The Granger causality in the frequency domain between the US EPU and the MPRs shows that US EPU significantly influences the MPRs positively in the long run. The findings of our study will provide the opportunity to African economic policymakers to be alert on the developments in the global economy and the impacts of such developments on the local economies so that proactive policy measures could be taken to avert any potential economic downturn of these countries. The rest of the study is structured as follows: Section 2 reviews the relevant literature. Sections 3 deals with the methodology and data while Section 4 discusses the results. Finally, Section 5 concludes the study.

\section{LITERATURE REVIEW}

Measuring the size of EPU and its impact on other macroeconomic variables has attracted the increasing interest of scholars, investors, and policymakers. Different methods have been applied by researchers from academia, economic policymakers, and the business community, all aiming at assessing the negative impact of rising EPU on other economic variables such as stock market returns (Sum (2012); Mensi et al. (2014); Balcilar, Bekiros, and Gupta (2017); Asafo-Adjei et al. (2020); Adam (2020)), oil prices (Balcilar et al., 2017), 
exchange rates (Olanipekun, Gungor, \& Olasehinde-Williams, 2019), etc., with some mixed results. In terms of EPU impact on stock markets, for example, Sum (2012) applied a vector autoregression analysis to examine the relationship between US news-based EPU and stock markets in the BRICS (Brazil, Russia, India, China and South Africa) and found negative relationship between stock market excess returns and increased changes in EPU. In contrast, Mensi et al. (2014) found no evidence to back the claim that US EPU has an effect on the BRICS' stock returns using a quantile regression methodology. With these contrasting results, EPU still has a significant impact on other macroeconomic variables. Thus, Gilchrist, Sim, and Zakrajšek (2014) showed that uncertainty causes financial distortions and influences the effective supply of credit, thereby generating countercyclical credit spreads and procyclical leverage which has a negative effect on investment using a panel of 11,303 US firms. Bhattarai, Chatterjee, and Park (2019) employed panel VAR technique to investigate the spillover indices of US uncertainty shocks on fifteen emerging market economies (EMEs) and find evidence of US uncertainty having harmful effects on the EME stock prices, exchange rates, country spreads, and capital inflows into them.

From a global perspective, US EPU is shown to have a great impact on both advanced and emerging market economies than other global EPU measures and it is more dominant in the literature. For example, Colombo (2013) shows that the US EPU leads to a larger fall in European industrial production and prices than the European Union EU EPU itself. Sum (2013) used Granger causality tests to investigate the effects of US EPU on five ASEAN countries (Indonesia, Malaysia, Philippines, Singapore, and Thailand) and found a harmful impact of US EPU on stock market returns of related countries. In addition, Chulia, Gupta, Uribe, and Wohar (2017) assessed US policy and US equity market uncertainty impact on domestic and other market return. Their findings suggest that an uncertainty shock lessens stock market returns in both developed and developing countries in uncertain times. Furthermore, Caggiano, Castelnuovo, and Figueres (2017) applied a nonlinear smooth transition VAR to estimate the asymmetric spillover impact of a US EPU shock on the unemployment rates of the G7 economies including Brazil taking into account the phase of the business cycles in those countries such as in expansions or in recessions. Their study revealed that the US EPU shock exerts a substantial effect on the unemployment rate in those countries, particularly during recessions.

Even though studies linking US EPU and other EPUs with global dimension to macroeconomic variables are well abound in the literature, most of these studies have not investigated the impact of EPU on MPD of either advance or developing countries. Few studies that focus on spillovers of international uncertain events using US monetary policy uncertainty (MPU) as one of the determinants of EPU in the US examine the US MPU spillovers through the bank lending channel and emerging market economy credit cycles (see Bauer and Neely (2014); Bruno and Shin (2015); Brauning and Ivashina (2020)). However, the focus of these studies was not explicitly on the impact of US EPU on MPD of other countries but rather on financial conditions, asset prices and economic activity abroad. There is, therefore, a huge gap in the existing literature on studies focusing on the EPU spillover transmissions to MPD of international economies, most especially US EPU spillover transmission to developing countries such as the African countries. We, therefore, fill the gap by investigating the impact of US EPU on MPD of four African countries including Egypt, South Africa, Namibia, and Ghana and to observe how economic policymakers of these countries adjust their MPDs that is proxied by MPR to the short-run deviations in the US EPU in the long-run equilibrium using threshold cointegration technique. 


\section{METHODOLOGY AND DATA DESCRIPTION}

\subsection{Threshold Cointegration and Error Correction Model}

To observe and analyse the nonlinear and asymmetric long-run relationship between MPD proxied by MPR of four African countries and US EPU, threshold cointegration pioneered by Enders and Siklos (2001) is followed. To proceed with our methodology, we must first establish the existence of long-run linear cointegration by performing the long-run cointegration test of Engle and Granger (1987). To perform this test, we assume that adjustment to the long-run equilibrium as well as increase or decrease in the deviation from the long-run equilibrium relationship is linear and symmetric. Therefore, the long-run relationship between country $i$ 's MPR and EPU in the US is defined as follows:

$$
M P R_{i, t}=\beta_{0}+\beta_{1} E P U_{t}+\varepsilon_{t}
$$

where $\beta_{0}$ is the constant term, $\beta_{1}$ is the coefficient that quantifies the long-run relationship between $M P R$ and $E P U$ and $\varepsilon_{t}$ is normally distributed error term with zero mean and constant variance.

After confirming the existence of long-run linear cointegration between the $M P R$ and the EPU from Engle and Granger (1987) cointegration test in Equation (1), we proceed to perform Enders and Siklos (2001) threshold cointegration. This is necessary because the Engle and Granger cointegration test is unable to detect the presence of a nonlinear long-run relationship between the variables. Since the adjustment to long-run equilibrium is nonlinear and asymmetric, we apply the threshold autoregressive (TAR) and momentum threshold autoregressive (M-TAR) models of Enders and Granger (1998) threshold cointegration to estimate the long-run cointegration and nonlinear adjustments of $M P R$ to the positive or negative deviations of the EPU in the long-run equilibrium level. The TAR model specification is stated as follows:

$$
\Delta \varepsilon_{t}=I_{t} \rho^{+} \varepsilon_{t-1}+\left(1-I_{t}\right) \rho^{-} \varepsilon_{t-1}+\sum_{i=1}^{k} \gamma_{i} \Delta \varepsilon_{t-1}+\mu_{t}
$$

where $\varepsilon_{t}$ is the residual in Equation (1) which is substituted into Equation (2), $\mu_{t}$ is an independent identically distributed (iid) random variable with mean zero and constant variance. The $I_{t}$ denotes the Heaviside indicator function specified as:

$$
I_{t}=\left\{\begin{array}{l}
1 \\
0 \quad \text { if } \varepsilon_{t} \geq \tau \\
0 \quad \varepsilon_{t}<\tau
\end{array}\right.
$$

$\tau$ represents the threshold value suggested endogenously by Chan (1993). To specify the MTAR model, we replace $I_{t}$ and $\varepsilon_{t}$ in Equation (2) respectively by $M_{t}$ and the change in the previous period's residual level $\Delta \varepsilon_{t}$. The Heaviside indicator function $M_{t}$ is stated as:

$$
M_{t}= \begin{cases}1 & \text { if } \Delta \varepsilon_{t} \geq \tau \\ 0 & \text { if } \Delta \varepsilon_{t}<\tau\end{cases}
$$


It should be noted that if $\varepsilon_{t-1}\left(\Delta \varepsilon_{t-1}\right)$ is above the threshold value $\tau$, then the adjustment is $\rho^{+} \varepsilon_{t-1}\left(\rho^{+} \Delta \varepsilon_{t-1}\right)$. On the other hand, if $\varepsilon_{t-1}\left(\Delta \varepsilon_{t-1}\right)$ is below the threshold value $\tau$, then the adjustment is $\rho^{-} \varepsilon_{t-1}\left(\rho^{-} \Delta \varepsilon_{t-1}\right)$. Three stages are followed to execute the threshold procedure. In the first stage, the TAR and M-TAR models for the cointegration procedure are estimated. The purpose of this stage is to test the null hypothesis of no cointegration (ie $H_{o}: \rho^{+}=\rho^{-}=0$ ) by comparing the critical values of the F-statistic with their corresponding actual value $\Phi$ with respect to Enders and Siklos (2001). If the test rejects the null hypothesis of no cointegration, then there exists a long-run relationship between MPR of the $i^{\text {th }}$ country and US EPU. Once the null hypothesis of no cointegration is rejected, we proceed to the second stage where the null hypothesis of symmetric adjustment $\left(H_{0}: \rho^{+}=\rho^{-}\right)$in the longrun equilibrium is tested. If the null hypothesis of symmetry is rejected, that is $\left|\rho^{+}\right| \neq\left|\rho^{-}\right|$, then there is evidence to suggest the existence of nonlinear threshold cointegration between MPR of country $i$ and US EPU and therefore the speed of adjustments to positive and negative divergence to the long-run equilibrium relationships are not the same. After establishing the existence of cointegration and nonlinear adjustments to the long-run equilibrium, we execute stage three where the threshold vector error correction model (TVECM) required to observe how the MPRs of the countries adjust to the short-run deviations in US EPU in the long-run equilibrium. We specify the TAR version of the TVECM for MPR of country $i$ and US EPU as below:

$$
\begin{aligned}
\Delta M P R_{i, t}=\alpha_{0}+ & I_{t} \rho^{+} \varepsilon_{t-1}+\left(1-I_{t}\right) \rho^{-} \varepsilon_{t-1} \\
& +\sum_{j=1}^{n} \alpha_{j} \Delta M P R_{t-j}+\sum_{j=1}^{n} \beta_{j} \Delta E P U_{t-j}+\mu_{t}
\end{aligned}
$$

where $\rho^{+}$and $\rho^{-}$represent the speed of adjustment parameters for positive (above) and negative (below) deviations (long-run regression coefficients) respectively for $M P R$ of country $i$ from its long-run equilibrium and $\alpha_{0}$ is the constant term. $\Delta E P U_{t-j}$ is the adjustment of US EPU in the short run, $\alpha_{j}$ and $\beta_{j}$ are the coefficients on the lagged change terms and $\mu_{t}$ denotes a white noise disturbance term. To specify the M-TAR of the TVECM, we simply replace $I_{t}$ and $\varepsilon_{t-1}$ respectively in Equation (5) by $M_{t}$ and $\Delta \varepsilon_{t-1}$.

According to Geweke (1982) and Hosoya (1991), the parameters of vector autoregression (VAR) model comprise of complex nonlinear functions and this complicates the statistical inference for the feedback measures over time. Because we want to observe the causal links between a country's MPR and US EPU which change according to frequency such as the short-run or long-run, we follow a Granger causality test in the frequency domain introduced by Breitung and Candelon (2006). We use the spectral frequency domain approach to observe the causal relationship between two time series variables based on bivariate spectral density matrix of VAR at different frequencies. According to Breitung and Candelon (2006), the null hypothesis $\left(H_{0}\right): M_{y \rightarrow x}(\omega)=0$ corresponds to $H_{0}: R(\omega) \beta=0$, where $\beta$ is the vector of the coefficients on the MPR of country $i$ and,

$$
R(\omega)=\left(\begin{array}{llll}
\cos (\omega) & \cos (2 \omega) & \ldots & \cos (p \omega) \\
\sin (\omega) & \sin (2 \omega) & \ldots & \sin (p \omega)
\end{array}\right)
$$


The F-statistics in Equation (6) is distributed as $F(2, T-2 p)$ for $\omega \in(0, \pi)$, where $T$ is the number of observations that measure the VAR model of order $p$. Estimating causal relationships in a frequency domain helps to observe nonlinearity and causality cycles for high or low frequencies. Because the relationships between the MPR of each country and US EPU are presented in a VAR system, the bi-directional relationships between MPR of country $i$ and US EPU in the long- and short-run are stated as follows:

$$
\begin{aligned}
M P R_{i, t} & =\sum_{j=1}^{p} \delta_{j} M P R_{i, t-j}+\sum_{j=1}^{p} \varphi_{j} E P U_{t-j}+\mu_{t} \\
E P U_{t} & =\sum_{j=1}^{p} \delta_{j} E P U_{t-j}+\sum_{j=1}^{p} \varphi_{j} M P R_{i, t-j}+\mu_{t}
\end{aligned}
$$

where $\delta$ and $\varphi$ are the regression coefficients and $\mu_{t}$ is the error term with zero mean and constant variance.

\subsection{Data and Data Description}

We use monthly data of MPR of the four African countries sourced from International Financial Statistics website with time stamps ranging from March 1998 to April 2020. The MPRs represent the interest rates at which the respective central banks of the countries lend to commercial banks and they are used to proxy the MPDs in this study. Also, the US EPU with monthly frequency covering the period March 1998 to April 2020 that is compiled by Baker, Bloom, and Davis (2016) is sourced from Policy Uncertainty (2020)). The US EPU index is proxied by news coverage frequency of policy-related economic issues. The range of the dataset is chosen based on the maximum available data for the countries. Figure no. 1 represents the time series plots of MPR of Egypt, Ghana, Namibia and South Africa and US EPU. In Figure no. 1, we observe co-movements among the MPRs of the countries, most especially between Namibia and South Africa since they are located within the same subregion in Africa and are highly integrated. In addition, all the MPRs decline towards the end of the sample period. By observing the relationships between US EPU and the MPRs in Figure no. 1 which is the focus of this study, we realise that the aftermath of September 11, 2001 terrorist attack on the US, that is between 2002 and 2003 and the Global Financial Crises that occurred between 2007 and 2008 show high co-movement between US EPU and MPR of each country. Our observation confirms the claim that the US is currently the central country (Gupta et al., 2020) and that its economic turbulence impacts other countries (Zhang et al., 2019) through its trade and financial channels (IMF, 2013).

Table no. 1 displays the descriptive statistics of the variables used in this study from the period March 1998 to April 2020. For the MPR variables, Ghana's MPR is high on average compared to the other countries' MPRs, indicating high interest rate in Ghana during the sample period while a country with the lowest MPR is Namibia. In terms of relative stability, Ghana's MPR is less stable because of its high standard deviation and a country with a relatively stable interest rate is Egypt having the lowest standard deviation. 


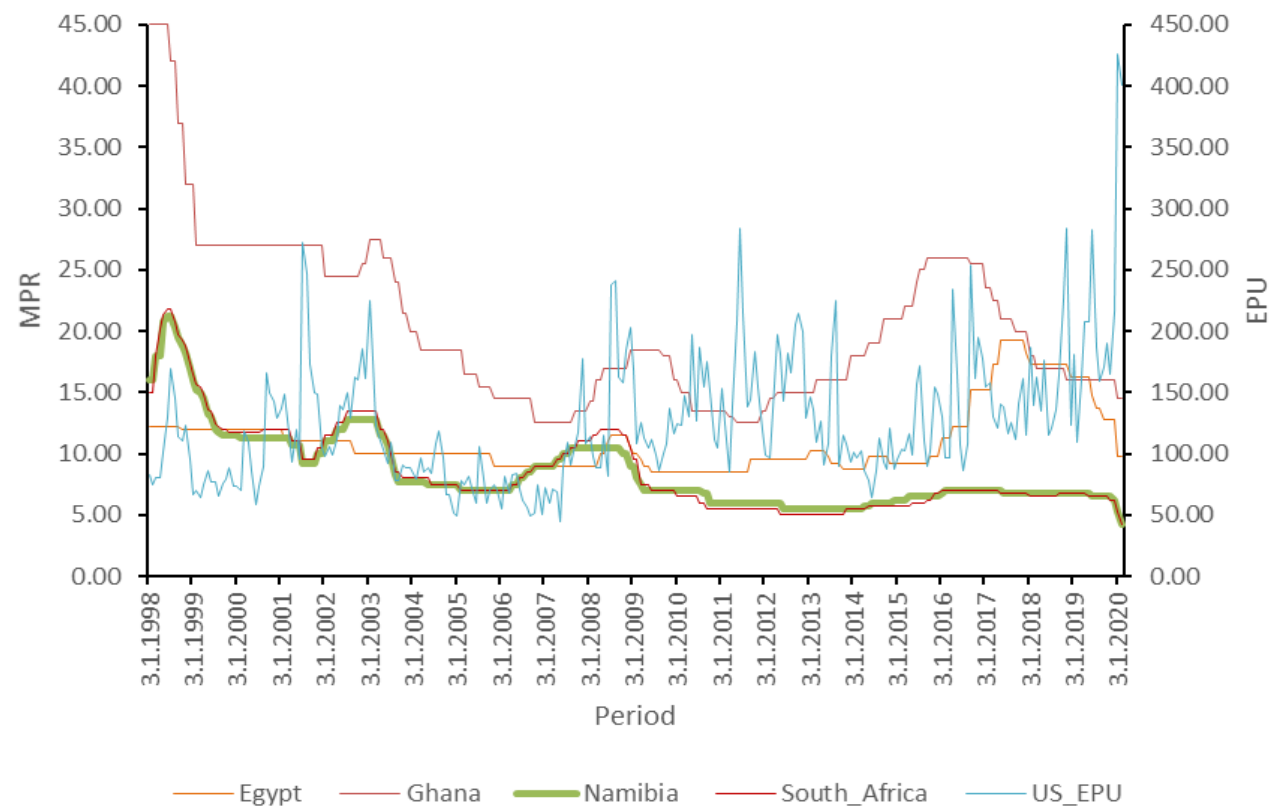

Figure no. 1 - Time series plots of the variables

Table no. 1 - Descriptive statistics

\begin{tabular}{|c|c|c|c|c|c|}
\hline & MPR_E & MPR_G & MPR_N & MPR_S & US_EPU \\
\hline Mean & 11.0442 & 20.3853 & 8.562 & 8.6452 & 125.6713 \\
\hline Min & 8.5 & 12.5 & 4.25 & 4.25 & 44.7828 \\
\hline $\operatorname{Max}$ & 19.25 & 45 & 21.25 & 21.85 & 425.9029 \\
\hline Std. Dev. & 2.6606 & 6.7736 & 3.2049 & 3.5249 & 54.1638 \\
\hline Skewness & 1.5545 & 1.3948 & 1.7117 & 1.4595 & 1.7034 \\
\hline Kurtosis & 1.6946 & 2.5481 & 3.135 & 2.1365 & 5.2539 \\
\hline Jarque-Bera & $141.52 *$ & $161.58 *$ & $243.54 *$ & $147.96 *$ & $443.34 *$ \\
\hline Shapiro & $0.7968 *$ & $0.8559 *$ & $0.8066^{*}$ & $0.8393 *$ & $0.8822 *$ \\
\hline
\end{tabular}

Note: * denotes the rejection of null hypothesis at $5 \%$ significant level

The distributions of all the MPRs are significantly different from normality because the distributions are all positively skewed with fat tails as these are respectively indicated by the coefficients of skewness and kurtosis. Both Jarque-Bera and Shapiro tests are shown in Table no. 1 confirm that the distributions of the MPRs are significantly different from a normal distribution. Furthermore, there is high fluctuation in US EPU as the gap between the minimum and the maximum of its EPU (the range) is wide with a high standard deviation and this makes the US EPU less stable over the sample period. The skewness and kurtosis values as well as Jarque-Bera and Shapiro tests show that the distribution of US EPU is significantly different from a normal distribution. 


\section{DISCUSSION OF RESULTS}

\subsection{Unit Root Test}

Because the cointegration test can only be performed on variables that are not stationary, we first perform unit root test to ascertain whether the variables are stationary or not using an autoregressive model. We apply unit root test techniques such as the Perron (1990) and Zivot and Andrews (2002) unit root tests to check whether the series is stationary or not. The model is defined by the equation:

$$
\Delta x_{t}=\emptyset x_{t-1}+\sum_{i=1}^{k-1} \lambda_{i} x_{t-i}+\mu_{t}+v_{t}
$$

where $x_{t}$ is the series of $\mathrm{T}$ observations, $\mu_{t}=\mu_{0}+\mu_{1} t$ is the deterministic terms $\left(\mu_{0} \neq 0\right.$ implies constant term and $\mu_{1} \neq 0$ implies deterministic trend) and $v_{t}$ is a white noise process.

Table no. 2 presents the results of Perron (1990) and Zivot and Andrews (2002) unit root tests of all the variables. The null hypothesis of all the series at the level having unit root cannot be rejected at 5\% level of significance in the presence of structural breaks. However, after taking the first difference, the variables are found to be stationary under the unit root tests indicating that the series are integrated of order 1, that is $I(1)$. The structural breaks for Egypt's and Ghana's MPRs occur around 2016 which show the spillover effect of the 2015 Chinese stock market crash. For the case of Namibia and South Africa, the structural breaks occur around 2001, highlighting the incidence of September 11 terrorist attack on the United States. These observations imply how vulnerable the countries are to global adverse events.

\subsection{Assessing the Nonlinear Behaviour of the Series}

To ascertain the nonlinear behaviour of the variables, we employ Brock-DechertScheinkman (BDS) test proposed by Brock (1991) which has high power against a vast class of linear, nonlinear and nonstationary models. The test is a nonparametric test derived from the correlation integral which is a measure of spatial correlation of scattered points in the mdimensional space. Given a time series $y_{t}$ which is embedded in the m-space by forming $\mathrm{m}$ histories $y_{t}^{m}=\left(y_{t}, y_{t-1}, \ldots, y_{t-m+1}\right)$, where $t=1,2, \ldots, T-m$ and embedded dimension $m \geq 2$. The correlation integral which counts the proportion of points in m-dimensional hyperspace that are within a distance $\epsilon$ of each other is given by:

$$
C_{m} T(\epsilon)=\frac{2}{(T-m+1)} \sum_{t<m} I_{\epsilon}\left(y_{t}^{m}-y_{s}^{m}\right)
$$

where $I_{\epsilon}$ is an indicator function defined by:

$$
I_{\epsilon}= \begin{cases}1, & \text { if }\left\|y_{t}^{m}-y_{s}^{m}\right\|<\epsilon \\ 0, & \text { if }\left\|y_{t}^{m}-y_{s}^{m}\right\| \geq \epsilon\end{cases}
$$

and $\|$.$\| denotes the supremum norm (sup norm). The BDS test shows that under the null$ hypothesis that the observed series $y_{t}$ is independent and identically distributed (iid), then $C_{m, I}(\epsilon)-C_{I, T}\left(C_{I, T}\right)^{m}$ is with probability 1 as the sample size $T$ tends to infinity and $\epsilon$ tends to 0 . 
Table no. 2 - Unit root test results

\begin{tabular}{ccrlcc}
\hline \multicolumn{7}{c}{ Level } & Break Date & Statistics & First Difference & Break Date & Statistics \\
\hline MPR_E & $2016 \mathrm{M} 10$ & -3.0697 & $\Delta$ MPR_E & $2016 \mathrm{M} 10$ & $-11.6698^{*}$ \\
MPR_G & $2016 \mathrm{M} 10$ & -2.0283 & $\Delta$ MPR_G & $2015 \mathrm{M} 09$ & $-6.4247^{*}$ \\
MPR_N & $2001 \mathrm{M} 10$ & -3.1817 & $\Delta$ MPR_N & $2003 \mathrm{M} 10$ & $-6.9274^{*}$ \\
MPR_S & $2001 \mathrm{M} 10$ & -3.584 & $\Delta$ MPR_S & $2009 \mathrm{M} 05$ & $-8.3000^{*}$ \\
US_EPU & $2013 \mathrm{M} 10$ & -4.8434 & $\Delta$ US_EPU & $2016 \mathrm{M} 11$ & $-15.1186^{*}$ \\
\hline \multicolumn{7}{c}{ Zivote Andrew } \\
\hline Level & Break Date & Statistics & First Difference & Break Date & Statistics \\
\hline MPR_E & $2016 \mathrm{M} 11$ & -2.7587 & $\Delta$ MPR_E & $2016 \mathrm{M} 11$ & $-11.6908^{*}$ \\
MPR_G & $2014 \mathrm{M} 02$ & -3.6246 & $\Delta$ MPR_G & $2016 \mathrm{M} 01$ & $-8.8046^{*}$ \\
MPR_N & $2001 \mathrm{M} 10$ & -3.1699 & $\Delta$ MPR_N & $2002 \mathrm{M} 11$ & $-8.7893^{*}$ \\
MPR_S & $2001 \mathrm{M} 10$ & -3.5831 & $\Delta$ MPR_S & $2002 \mathrm{M} 11$ & $-8.8166^{*}$ \\
US_EPU & $2003 \mathrm{M} 05$ & -4.9214 & $\Delta$ US_EPU & $2001 \mathrm{M} 11$ & $-14.9857^{*}$ \\
\hline Note: $*$ denotes the rejection of null hypothesis at $5 \%$ significance level. Critical values are from McKinnonn $(1996)$
\end{tabular}

The BDS test statistic having limiting standard normal distribution is stated as follows:

$$
F_{m, I}(\epsilon)=\frac{T^{\frac{1}{2}} C_{m, I}(\epsilon)-C_{I, T}(\epsilon)^{m}}{\sigma_{m . I}(\epsilon)}
$$

where $\sigma_{m . I}(\epsilon)$ is a nontrivial function of the correlation integral.

Table no. 3 presents the test results of BDS test pioneered by Brock (1991). The results as presented in Table no. 3 show that the null hypothesis of the series variables being iid is rejected at 5\% level suggesting that all the variables are non-linearly dependent. This implies that the variables are inherently non-linear and exhibit chaotic behaviours - see Brock (2018). Therefore, using a nonlinear model to proceed with the analysis to capture the nonlinear dynamics revealed by the BDS test is well in line.

Table no. 3 - BDS test results

\begin{tabular}{cccccc}
\hline m & MPR_E & MPR_G & MPR_N & MPR_S & US_EPU \\
\hline 2 & $0.196681^{*}$ & $0.197187^{*}$ & $0.194742^{*}$ & $0.201240^{*}$ & $0.068966^{*}$ \\
3 & $0.333350^{*}$ & $0.333422^{*}$ & $0.331000^{*}$ & $0.334538^{*}$ & $0.110879^{*}$ \\
4 & $0.426205^{*}$ & $0.427401^{*}$ & $0.426457^{*}$ & $0.422944^{*}$ & $0.130206^{*}$ \\
5 & $0.489264^{*}$ & $0.490956^{*}$ & $0.491893^{*}$ & $0.479380^{*}$ & $0.140434^{*}$ \\
6 & $0.531554^{*}$ & $0.533009^{*}$ & $0.536550^{*}$ & $0.515076^{*}$ & $0.139919 *$ \\
\hline \multicolumn{7}{l}{ Note: * denotes rejection of null hypothesis at 5\% level. m represents embedding dimensional points. }
\end{tabular}

\subsection{Engle-Granger Cointegration Test Results}

As the first step to unearth the long-run relationship between the MPRs and US EPU, we perform Engle-Granger cointegration test procedure by estimating Equation (1). The test results as presented in Table no. 4 indicate the models' residuals for all MPR-EPU combinations and the null hypothesis of no cointegration is rejected for all models at $5 \%$ level of significance. The findings imply that each MPR and the US EPU are cointegrated, 
confirming the long-run relationships between each country's MPR and US EPU. We can therefore infer from Table no. 4 that a change in US EPU causes managers of each country's Central Bank to review its policy decisions by adjusting its MPR depending on the direction of movement in the US EPU to control inflation.

Table no. 4 - Engle-Granger cointegration results

\begin{tabular}{lcccc}
\hline & MPR_E/ US_EPU & MPR_G/ US_EPU & MPR_N/US_EPU & MPR_S/ US_EPU \\
\hline Test statistics & $-2.2555^{*}$ & $-4.1485 *$ & $-5.3538^{*}$ & $-4.9542 *$ \\
\hline Note: $*$ denotes $5 \%$ significant level with corresponding critical value equal to -1.95 . Each column represents model's
\end{tabular}
residual for each MPR model of the African countries.

\subsection{Enders-Siklos Cointegration Test Results}

The nonlinear threshold cointegration between the MPRs and US EPU is investigated using Enders and Siklos (2001) test and the results are presented in Table no. 5 and no. 6. Both Tables show threshold effects and focus on convergence, threshold cointegration and adjustment in the long-run equilibrium following divergence in the US EPU. The columns in Table no. 5 and no. 6 are described as follows: the first column shows the threshold cointegration model specifications, the second and third columns respectively indicate the values of the adjustment parameters $\rho^{+}$and $\rho^{-}$. The fourth and fifth columns show F-statistics of the null hypothesis of no cointegration and symmetric adjustment, respectively. Finally, the sixth column shows the conclusions drawn from the cointegration and symmetric adjustment tests.

Specifically, Table no. 5 presents parameter estimates of TAR specification of the threshold cointegration model in Equation (2) by assuming the threshold value to be zero for each model which is deterministic. The point estimates in the TAR model show convergence of long-run equilibrium and that the speed of convergence for positive deviations from longrun equilibrium is faster than the speed of convergence for negative deviation for Ghana's MPR model since the larger of the t-statistics is the positive adjustment parameter $\rho^{+}$which is greater than the $5 \%$ critical value. Even though, the larger of the t-statistics is the positive adjustment parameter $\rho^{+}$in both Namibia's and South Africa's MPR models which is significant at $5 \%$ level, the speed of convergence for positive deviations is not significantly faster than the speed of convergence for negative deviations as these are confirmed by the symmetric adjustment test results in column 5 of Table no. 5 .

Table no. 5 - Enders-Siklos cointegration test results according to TAR model

\begin{tabular}{llllll}
\hline Model & \multicolumn{1}{c}{$\boldsymbol{\rho}^{+}$} & \multicolumn{1}{c}{$\boldsymbol{\rho}^{-}$} & $\boldsymbol{\rho}^{+}=\boldsymbol{\rho}^{-}=\mathbf{0}$ & $\boldsymbol{\rho}^{+}=\boldsymbol{\rho}^{-}$ & Conclusion \\
\hline MPR_E $\sim$ US_EPU & $-0.031^{*}$ & $-0.051^{*}$ & $2.946^{*}$ & 0.354 & Cointegration exists/ \\
& $(-1.724)$ & $(-1.794)$ & {$[0.054]$} & {$[0.552]$} & Symmetric adjustment \\
MPR_G $\sim$ US_EPU & $-0.051^{* *}$ & -0.009 & $11.426^{* *}$ & $5.355^{* *}$ & Cointegration exists/ \\
& $(-4.738)$ & $(-0.602)$ & {$[0.000]$} & {$[0.021]$} & Asymmetric adjustment \\
MPR_N $\sim$ US_EPU & $-0.054^{* *}$ & -0.032 & $10.458^{* *}$ & 0.934 & Cointegration exists/ \\
& $(-4.278)$ & $(-1.62)$ & {$[0.000]$} & {$[0.335]$} & Symmetric adjustment \\
MPR_S $\sim$ US_EPU & $-0.044^{* *}$ & -0.027 & $7.355^{* *}$ & 0.532 & Cointegration exists/ \\
& $(-3.548)$ & $(-1.472)$ & {$[0.001]$} & {$[0.466]$} & Symmetric adjustment \\
\hline
\end{tabular}

Note: $* *$ and $*$ respectively denote significant levels at $5 \%$ and $10 \%$. Numbers in parenthesis and square brackets are $\mathrm{t}$-values and p-values respectively. 
But on the contrary, the larger of the t-statistics is the negative adjustment parameter $\rho^{-}$ for Egypt's MPR model which is greater than the 5\% critical value. However, the speed of convergence for negative deviation is not significantly faster than the speed of convergence for positive deviation as this is confirmed by the symmetric adjustment test result in column 5 . For all the models, the F-joint statistics $\left(H_{0}: \rho^{+}=\rho^{-}=0\right)$ are greater than the $5 \%$ critical value implying the null hypothesis of no cointegration is rejected at $5 \%$ significance level. This suggests a long-run equilibrium relationship between each country's MPR and US EPU. Moreover, the F-equal statistics $\left(H_{0}: \rho^{+}=\rho^{-}\right)$that test the null hypothesis of symmetric adjustment, is greater than 5\% critical value for Ghana's MPR model indicating that the null hypothesis of symmetric adjustment is rejected. This implies that Ghana reacts quickly to adjust its MPR when US EPU rises more than reacting to a decline in US EPU. However, the null hypothesis for symmetric adjustment to positive and negative deviations cannot be rejected for the other three models (Egypt, Namibia and South Africa) and that the rate at which these countries respond to adjusting their MPRs to rising and declining US EPU is at par.

Because the value of the threshold is not always zero and is typically unknown, we follow the approach of Chan (1993) to obtain consistent estimates of the threshold. The threshold values obtained for estimating each M-TAR model are selected based on Akaike Information Criteria (AIC). Therefore, a threshold with minimum AIC for Egypt's MPR model is -1.44 , Ghana's MPR model is -0.317 , Namibia's MPR model is -0.326 and South Africa MPR model is -0.282 . Table no. 6 presents a similar analysis as in Table no. 5 using the M-TAR specification to verify asymmetric movement in a country's MPR to changes in US EPU. Contrary to the TAR models, the larger of the t-statistics is the negative adjustment parameter $\rho^{-}$of the MPR models for Ghana, Namibia, and South Africa, which is greater than the $5 \%$ critical value while the larger of the t-statistics is the positive adjustment parameter $\rho^{+}$of the MPR model for Egypt, which is greater than the $5 \%$ critical value.

Table no. 6 - Enders-Siklos cointegration test results according to M-TAR model

\begin{tabular}{llllll}
\hline Model & \multicolumn{1}{c}{$\boldsymbol{\rho}^{+}$} & \multicolumn{1}{c}{$\boldsymbol{\rho}^{-}$} & $\boldsymbol{\rho}^{+}=\boldsymbol{\rho}^{-}=\mathbf{0}$ & $\boldsymbol{\rho}^{+}=\boldsymbol{\rho}^{-}$ & Conclusion \\
\hline MPR_E $\sim$ US_EPU & $-0.039^{* *}$ & -0.003 & $3.083^{*}$ & 0.048 & Cointegration exists/ \\
& $(-2.481)$ & $(-0.031)$ & {$[0.048]$} & {$[0.665]$} & Symmetric adjustment \\
MPR_G $\sim$ US_EPU & $-0.021^{* *}$ & $-0.074^{* *}$ & $12.885^{* *}$ & $8.095^{* *}$ & Cointegration exists/ \\
& $(-2.015)$ & $(-4.659)$ & {$[0.000]$} & {$[0.005]$} & Asymmetric adjustment \\
MPR_N $\sim$ US_EPU & -0.016 & $-0.098^{* *}$ & $16.399^{* *}$ & $11.956^{* *}$ & Cointegration exists/ \\
& $(-1.151)$ & $(-5.457)$ & {$[0.000]$} & {$[0.001]$} & Asymmetric adjustment \\
MPR_S $\sim$ US_EPU & -0.012 & $-0.080^{* *}$ & $11.589^{* *}$ & $8.557^{* *}$ & Cointegration exists/ \\
& $(-0.858)$ & $(-4.608)$ & {$[0.000]$} & {$[0.004]$} & Asymmetric adjustment \\
\hline
\end{tabular}

Note: $* *$ and $*$ respectively denote significant levels at $5 \%$ and $10 \%$. Numbers in parenthesis and square brackets are t-values and p-values respectively.

This means that the speed of convergence for negative deviations in the long-run equilibrium is faster than the speed of convergence for positive deviations for Ghana's, Namibia's, and South Africa's MPR models while Egypt's MPR model is the reverse. For all four models, the null hypothesis of no cointegration $\left(H_{0}: \rho^{+}=\rho^{-}=0\right)$ is rejected because the value of F-joint statistics is greater than $5 \%$ critical value implying the presence of longrun equilibrium relationship between the MPRs and US EPU. Again, the null hypothesis of symmetric adjustment $\left(H_{0}: \rho^{+}=\rho^{-}\right)$is rejected for Ghana's, Namibia's and South Africa's MPR models, indicating the speed of adjustment of positive and negative deviations from 
long-run equilibrium are not the same and the adjustments are faster towards negative deviations than positive deviations. Thus, there is a quick monetary policy response by these countries whenever US EPU declines. For the case of Egypt, the null hypothesis of symmetric adjustment to positive and negative deviations cannot be rejected implying the country's monetary policy response rate to rising or declining US EPU is not different.

Because the results for the TAR and M-TAR specifications are contradictory, our findings are based on the M-TAR results. Our choice of the M-TAR model is because setting the Heaviside indicator using the change lag residuals $\left(\Delta \varepsilon_{t-1}\right)$ instead of the level lag residuals $\left(\varepsilon_{t-1}\right)$ can perform better than the pure TAR adjustment specification - see Hansen (1997). Also, according to Enders and Granger (1998) and Enders and Siklos (2001), the M-TAR specification is relevant especially when the adjustment is such that the series show more momentum in one direction than the other. Finally, the AIC values of all the M-TAR models which are not reported, are smaller than the TAR models, indicating better M-TAR models fit. Therefore, drawing our conclusion based on the M-TAR model shows that decline in US EPU causes Ghana, Namibia and South Africa to quickly soften their policy stance as a way of stimulating economic activities by making the cost of doing business less expensive compared to taking tight policy stance when US EPU rises. This is because declining US EPU decreases global economic uncertainty most especially in the emerging economies and that uncertainties surrounding underlying price pressures such as currency depreciation, high oil prices that lead to hikes in transportation cost, high interest rates and high output gap reduces, resulting in central bank managers cutting their MPRs to ensure economic growth.

\subsection{The Error Correction Model Estimation Results in M-TAR Specification}

We continue the asymmetric adjustment process for having found evidence of asymmetric adjustment for the MPR models for Ghana, Namibia, and South Africa by using M-TAR error correction model (M-TVECM) in Equation (5) to investigate the movement of variables to the long-run equilibrium relationship. In all, four M-TVECM comprising Egypt's MPR and US EPU pair, Ghana's MPR and US EPU pair, Namibia's MPR and US EPU pair, and South Africa's MPR and US EPU pair, are estimated. Table no. 7 presents the results of the adjustment of asymmetries for US EPU on the MPRs of Egypt, Ghana, Namibia, and South Africa. The results show that the speed of adjustment of the negative deviations is more rapid than the speed of adjustment of the positive deviations for Ghana's, Namibia's and South Africa's MPR models while for the case of Egypt, the speed of adjustment of the positive deviation is higher than the speed of adjustment of the negative deviation. To be more specific, the adjustment of the negative deviation of US EPU is significant at 5\% level showing a positive relationship between US EPU and Ghana' MPR in the short-run even though, the impact of US EPU on Ghana's MPR is not immediate. The finding suggests that Ghana responds more rapidly to soften its policy stance whenever US EPU declines to stimulate economic growth when the uncertainties of the underlying price pressures reduce than tightening its policy stance for rising US EPU. In addition, US EPU shows a significant positive impact on Namibia's MPR and the negative adjustment parameter is significant at 5\% level showing a significant positive relationship between US EPU and Namibia's MPR in the short run. The finding implies that Namibia central bank's monetary policy response to changes in US EPU is immediate and it quickly reduces its MPR when US EPU declines in order to stimulate economic growth. 
Table no. 7 - M-TVECM coefficient estimates

\begin{tabular}{|c|c|c|c|c|}
\hline & MPR_E US_EPU & MPR_G US_EPU & MPR_N US_EPU & MPR_S US_EPU \\
\hline$\overline{\Delta U S \_E P U \_1}$ & & & $\begin{array}{c}0.0022 * * \\
(2.072)\end{array}$ & $\begin{array}{c}0.0025^{* *} \\
(2.331)\end{array}$ \\
\hline$\Delta U S \_E P U \_3$ & & $\begin{array}{c}0.0052 * * \\
(2.380)\end{array}$ & & \\
\hline$\Delta U S$ EPU_6 & $\begin{array}{c}-0.0032 * * \\
(-2.482)\end{array}$ & & & \\
\hline$\triangle M P R \_E \_2$ & $\begin{array}{c}0.1964 * * \\
(2.112)\end{array}$ & & & \\
\hline$\Delta$ MPR_G_2 & & $\begin{array}{c}0.364 * * \\
(2.729)\end{array}$ & & \\
\hline DMPR_G_3 & & $\begin{array}{c}0.2593 * * \\
(3.420)\end{array}$ & & \\
\hline$\Delta$ MPR_N_1 & & & $\begin{array}{c}0.2987 * * \\
(3.249)\end{array}$ & \\
\hline$\Delta$ MPR_S_1 & & & & $\begin{array}{c}0.4263 * * \\
(5.188)\end{array}$ \\
\hline$\Delta$ MPR_S_2 & & & & $\begin{array}{c}0.2579 * * \\
(3.072)\end{array}$ \\
\hline$\rho^{+}$ & $\begin{array}{c}-0.0244 * * \\
(-2.152)\end{array}$ & $\begin{array}{l}-0.0087 \\
(-0.924)\end{array}$ & $\begin{array}{c}0.0172 * \\
(1.845)\end{array}$ & $\begin{array}{c}-0.0195 * * \\
(-2.145)\end{array}$ \\
\hline$\rho^{-}$ & $\begin{array}{l}-0.0267 \\
(-0.452) \\
\end{array}$ & $\begin{array}{c}-0.0411 * * \\
(-2.688)\end{array}$ & $\begin{array}{c}-0.0637 * * \\
(-4.575)\end{array}$ & $\begin{array}{c}-0.0556 * * \\
(-4.757)\end{array}$ \\
\hline
\end{tabular}
represents MPR model for each African country.

Furthermore, US EPU significantly influences the MPR of South Africa in the short run and the adjustment of the negative deviation of US EPU is significant at 5\% level and higher than the positive adjustment parameter, indicating a positive relationship between US EPU and South Africa's MPR in the short run. The finding implies that South Africa's monetary policy response to declining US EPU is immediate and this action is taken to stimulate economic growth by making cost of doing business less expensive. The findings for these three countries (Ghana, Namibia, and South Africa) suggest that their monetary policy responses to rising US EPU are less rapid because they usually take enough time to observe the uncertainties surrounding the underlying price pressures before any concrete action is taken in order not to stifle economic growth. That is, businesses need cheap funding and when interest rates are low, businesses are more willing to expand to employ more people for an eventual reduction in the unemployment rate. Moreover, Egypt's monetary policy response to movements in US EPU is different from the other three countries since the positive adjustment parameter is significant at 5\% level showing a negative relationship between US EPU and Egypt's MPR in the short run though, but it adjusts its MPR slowly to movements in US EPU. The finding suggests that the central bank of Egypt responds to rising US EPU by reducing its policy rate to take advantage of capital flight from the international financial markets to emerging markets that are weakly integrated with the advanced economies. 


\subsection{Estimating causality between US EPU and the MPRs in the Frequency Domain}

The final investigation of the relationship between US EPU and the MPRs of the countries is carried out to explore the existence of short and long-run causality among the variables in the frequency domain by estimating Equations (6), (7) and (9). The causality test is performed at $5 \%$ level of significance with the test statistics lying in the interval $(0, \pi)$ and the frequencies correspond to a wavelength of $2 \pi / \omega \sim 2$ years. The critical value is determined by calculating the degree of freedom $(2, T-2 p)$ by setting $T$ to 266 total observations and VAR order $p$ to 4 to obtained degrees of freedom 2 and 258. Figure no. 2 shows Granger causality of US EPU and Egypt's MPR and at 5\% level of significance, US EPU Granger causes Egypt's MPR for frequencies for 5 to 33 months in the long run while Egypt's MPR does not significantly cause US EPU either in the short or long run. This result suggests unidirectional causality from US EPU to MPR of Egypt and that, Egypt's monetary policy stance is influenced by movement in US EPU in the long run.
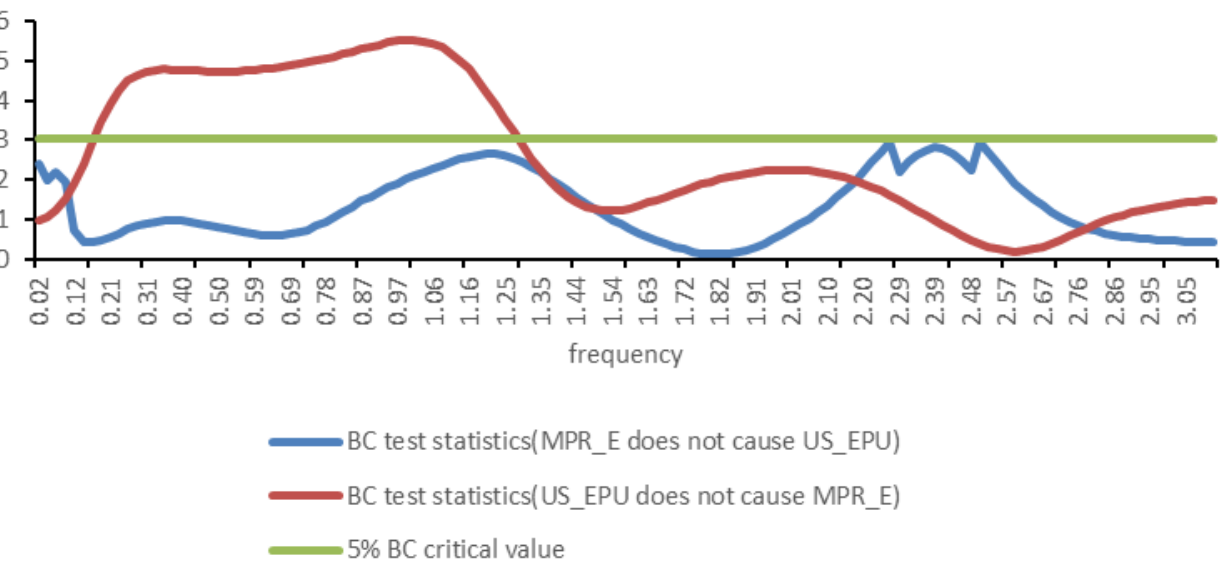

Note: The part of the lines above the critical value-line indicates rejection of the null the hypothesis of no Granger causality Figure no. 2 - The frequency domain causality between US EPU and Egypt's MPR.

Figure no. 3 shows the causality of US EPU and Ghana's MPR in the short and long run. US EPU Granger causes Ghana's MPR in the long run at frequencies significant at 5\% level for 10 to 11 months. On the other hand, Ghana's MPR does not significantly Granger cause US EPU in both short- and long-run, indicating unidirectional causality from US EPU to Ghana's MPR. The finding implies that Ghana's Central Bank takes a long time to adjust its policy stance with regards to changes in US EPU to enable it to observe the uncertainty dynamics of the underlying price pressures.

Figure no. 4 depicts the Granger causality results for US EPU and Namibia's MPR. The results reveal that US EPU Granger causes Namibia's MPR at frequencies significant at 5\% level for 15 to 16 months in the long run while Namibia's MPR does not significantly cause US EPU, indicating unidirectional causality from US EPU to Namibia's MPR. The finding shows that Namibia's monetary policy response to changes in US EPU takes long time while the country observes the uncertainties of its local economy which may call for a review of its policy stance. 


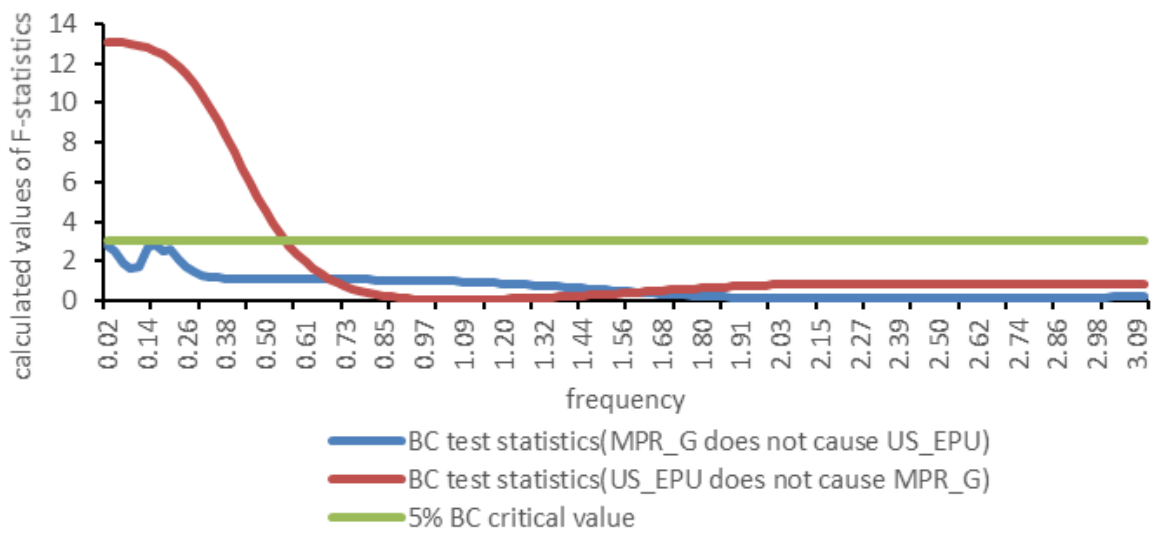

Note: The part of the lines above the critical value-line indicates rejection of the null hypothesis of no Granger causality Figure no. 3 - The frequency domain causality between US EPU and Ghana's MPR

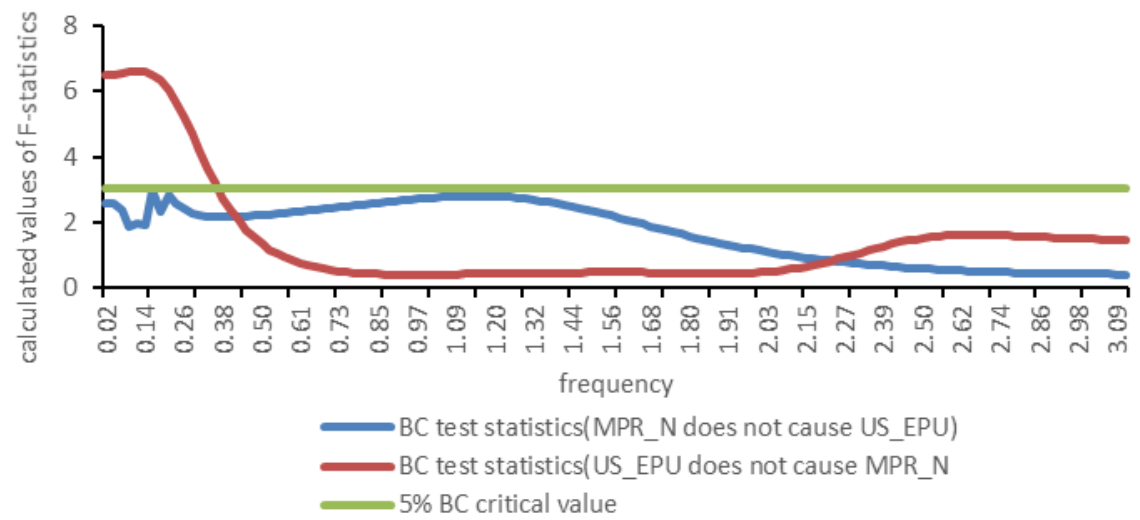

Note: The part of the lines above the critical value-line indicates rejection of the null hypothesis of no Granger causality Figure no. 4 - The frequency domain causality between US EPU and Namibia's MPR

Figure no. 5 exhibits Granger causality between US EPU and South Africa's MPR. At $5 \%$ level of significance, US EPU Granger causes South Africa's MPR at frequencies corresponding to 10 to 11 months in the long run while South Africa's MPR does not Granger cause US EPU. This unidirectional causality from US EPU to South Africa's MPR in the long run indicates that South Africa reacts slowly to changes in US EPU to review its policy stance.

The significant long run impact of US EPU on the MPRs of the countries confirms the long run equilibrium relationship between US EPU and the MPRs and this also shows that these African countries take long time to observe the level of uncertainty of the underlying price pressures in their economies in response to changes in US EPU. Based on the level of uncertainty of the price pressures because of changes in the level of US EPU informs the monetary policy action to be taken to stimulate economic growth and to restore confidence in their respective economies. 


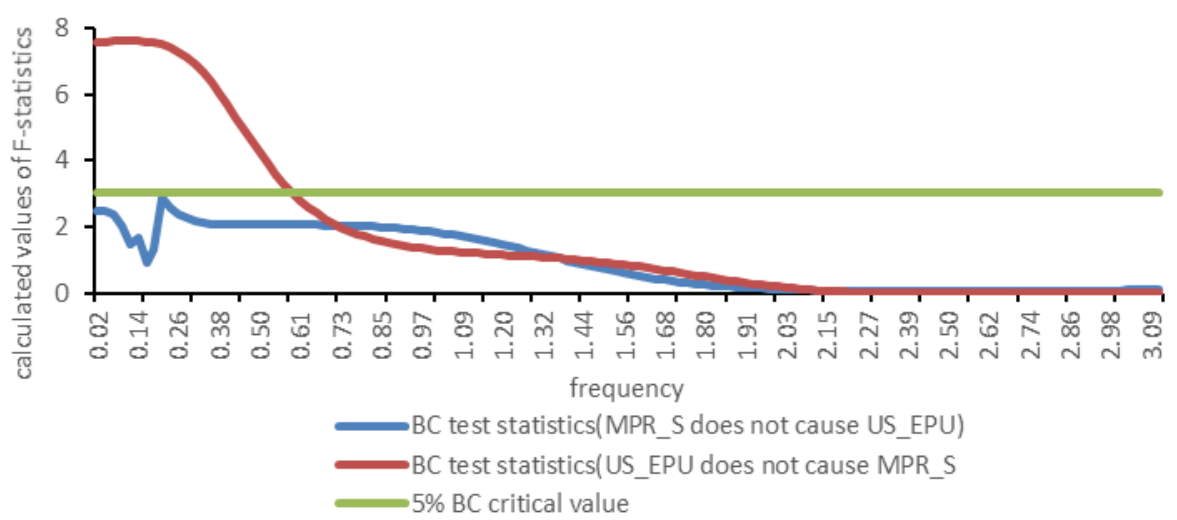

Note: The part of the lines above the critical value-line indicates rejection of the null hypothesis of no Granger causality Figure no. 5 - The frequency domain causality between US EPU and South Africa's MPR

\section{CONCLUSION}

We have investigated the impact of US EPU on MPRs of four African countries that comprise of Egypt, Ghana, Namibia, and South Africa from March 1998 to April 2020 using threshold cointegration approach. The impact of US EPU on the MPRs was assessed by examining the linear cointegration, asymmetric cointegration and causal relationships between the US EPU and MPR of each country. The Engle-Granger cointegration test provides evidence of the existence of long run equilibrium relationship between US EPU and each of the MPRs. Since Engle-Granger cointegration does not provide evidence of threshold adjustment in the long run equilibrium, we applied Enders-Siklos cointegration to both TAR and M-TAR models to capture the asymmetric response of each MPR to changes in US EPU in the long run equilibrium. Both the TAR and M-TAR models suggest the existence of threshold cointegration between US EPU and all the MPRs, showing long run equilibrium relationship between the variables. However, the null hypothesis of symmetric adjustment was not rejected for all models in the TAR specification apart from Ghana's MPR model which exhibits asymmetric adjustment and the speed of adjustment for positive deviation is more rapid than speed of adjustment for negative deviation from the long run equilibrium. For the M-TAR models with none-zero threshold value, the null hypothesis of symmetric adjustment was rejected for all models and the speed of adjustment for negative deviation was more rapid than the speed of adjustment for positive deviation, except Egypt's MPR model where the null hypothesis of symmetric adjustment was not rejected. In addition, the estimated TVECM using M-TAR specification shows that US EPU impact the MPRs in the short run and the adjustment processes are quicker for negative deviations. The findings show that Ghana, Namibia and South Africa review their policy rates downward more rapidly to declining US EPU to stimulate their economies for growth than reviewing the policy rates upward to rising US EPU for economic contraction. However, Egypt's monetary policy response is indifferent to rising or declining US EPU.

Moreover, assessment of the bivariate relationship between the US EPU and MPRs using the frequency domain causality in the short and long run shows unidirectional causality from US EPU to the MPRs in the long run. The findings indicate that US EPU Granger causes the 
MPRs in the long run but none of the MPRs Granger causes the US EPU. The implication of the findings is that the Central Banks of these African countries take time to react to movements in US EPU so that appropriate policy action that would spark economic growth is taken after observing the extent of uncertainties of the underlying price pressures. Our findings further suggest that MPDs of the African countries like any other emerging market economy or small open market economy do not influence the dynamics of the US economy. Even though these African countries' monetary policy objectives are inflation targeting, the Central Banks are concerned with economic growth and thus, respond more rapidly to review their policy stance downward than to review it upward to stimulate economic growth. Therefore, knowing the extent of exposure of African economies to uncertainties of the US economy would help Policymakers and Central Bank managers to adopt policy stance that would stimulate economic growth while having their eyes caught on inflation dynamics and the uncertainties of the underlying price pressures.

\section{ORCID}

Prince Mensah Osei (iD https://orcid.org/0000-0001-9963-9872 Anokye M. Adam (iD https://orcid.org/0000-0003-3830-1186

\section{References}

Adam, A. M. (2020). Susceptibility of stock market returns to international economic policy evidence from effective transfer entropy of Africa with the implication for open innovation. Journal of Open Innovation, 6(3), 71. http://dx.doi.org/10.3390/joitmc6030071

Asafo-Adjei, E., Agyapong, D., Agyei, S. A., Frimpong, S., Djimatey, R., \& Adam, A. M. (2020). Economic Policy Uncertainty and Stock Returns of Africa: A Wavelet Coherence Analysis. Discrete Dynamics in Nature and Society, 2020, 1-8. http://dx.doi.org/10.1155/2020/8846507

Baker, S. R., Bloom, N., \& Davis, S. J. (2016). Measuring Economic Policy Uncertainty. The Quarterly Journal of Economics, 131, 1593-1636. http://dx.doi.org/10.1093/qje/qjw024

Balcilar, M., Bekiros, S., \& Gupta, R. (2017). The Role of News-Based Uncertainty Indices in Predicting Oil Markets: A Hybrid Nonparametric Quantile Causality Method. Empirical Economics, 53(3), 879-889. http://dx.doi.org/10.1007/s00181-016-1150-0

Bauer, M. D., \& Neely, C. J. (2014). International channels of the Fed's unconventional monetary policy. Journal of International Money and Finance, 44, 24-46. http://dx.doi.org/10.1016/j.jimonfin.2013.12.007

Belke, A. B., Gros, D., \& Thomas, O. (2017). The effectiveness of the Fed's quantitative easing policy: New evidence based an international interest rate differential. Journal of International Money and Finance, 73, 335-349. http://dx.doi.org/10.1016/j.jimonfin.2017.02.011

Bhattarai, S., Chatterjee, A., \& Park, W. Y. (2019). Global spillover indices of US uncertainty. Journal of Monetary Economics, 114, 71-89. http://dx.doi.org/10.1016/j.jmoneco.2019.05.008

Bowman, D., Juan, M., \& Sapriza, L. H. (2014). U.S. Unconventional Monetary Policy and Transmission to Emerging Market Economies. Board of Governors of the Federal Reserve System, International Finance Discussion Papers 1109.

Brauning, F., \& Ivashina, V. (2020). U.S. monetary policy and emerging market credit cycles. Journal of Monetary Economics, 112(C), 57-76. http://dx.doi.org/10.1016/j.jmoneco.2019.02.005

Breitung, J., \& Candelon, B. (2006). Testing for short-and long-run causality: A frequency-domain $\begin{array}{llll}\text { approach. Journal of } & \text { 363-378. }\end{array}$ http://dx.doi.org/10.1016/j.jeconom.2005.02.004 
Brock, W. A. (1991). Nonlinear dynamics, chaos, and instability:statistical theory and economic evidence: MIT Press.

Brock, W. A. (2018). Nonlinearity and complex dynamics in economics and finance: The economy as an evolving complex system: CRC Press. http://dx.doi.org/10.1201/9780429492846-5

Bruno, V., \& Shin, H. S. (2015). Capital Flows and the Risk-taking Channel of Monetary Policy. Journal of Monetary Economics, 71, 119-132. http://dx.doi.org/10.1016/j.jmoneco.2014.11.011

Caggiano, G., Castelnuovo, E., \& Figueres, J. M. (2017). Economic policy uncertainty spillovers in booms and busts. SSRN. http://dx.doi.org/10.2139/ssrn.2972967

Castelnuovo, E., Lim, G., \& Pellegrino, G. (2017). A Short Review of the Recent Literature on Uncertainty. The Australian Economic Review, 50(1), 68-78. http://dx.doi.org/10.1111/14678462.12210

Chan, K. S. (1993). Consistency and limiting distribution of the least squares estimator of a threshold autoregressive model. Annals of Statistics, 21(1), 520-533. http://dx.doi.org/10.1214/aos/1176349040

Choi, S. (2018). The Impact of US Financial Uncertainty Shocks on Emerging Market Economies: An International Credit Channel. Open Economies Review, 29(1), 89-118. http://dx.doi.org/10.1007/s11079-017-9471-y

Chulia, H., Gupta, R., Uribe, J. M., \& Wohar, M. E. (2017). Impact of US uncertainties on emerging and mature markets: Evidence from a quantile-vector autoregressive approach. Journal of International Financial Markets, Institutions and Money, 48, 178-191. http://dx.doi.org/10.1016/j.intfin.2016.12.003

Colombo, V. (2013). Economic policy uncertainty in the US: Does it matter for the Euro area? Economics Letters, 121(1), 39-42. http://dx.doi.org/10.1016/j.econlet.2013.06.024

Dakhlaoui, I., \& Aloui, C. (2016). The Interactive Relationship between the US Economic Policy Uncertainty and BRIC Stock Markets. Inter Economics, 146, 141-157. http://dx.doi.org/10.1016/j.inteco.2015.12.002

Enders, W., \& Granger, C. W. J. (1998). Unit-root Tests and Asymmetric Adjustment with an Example Using the Term Structure of Interest Rates. Journal of Business \& Economic Statistics, 16, 304311. http://dx.doi.org/10.2307/1392506

Enders, W., \& Siklos, P. (2001). Cointegration and threshold adjustment. Journal of Business \& Economic Statistics, 19, 166-176. http://dx.doi.org/10.1198/073500101316970395

Engle, R. F., \& Granger, C. W. J. (1987). Co-integration and error correction: Representation, estimation, and testing. Econometrica, 55(2), 251-276. http://dx.doi.org/10.2307/1913236

Gabauer, D., \& Gupta, R. (2020). Spillovers across macroeconomic, financial and real estate uncertainties: A time-varying approach. Structural Change and Economic Dynamics, 52, 167-173. http://dx.doi.org/10.1016/j.strueco.2019.09.009

Geweke, J. (1982). Measurement of linear dependence and feedback between multiple time series. Journal of the American Statistical Association, 77(378), 304-313. http://dx.doi.org/10.1080/01621459.1982.10477803

Gilchrist, S., Sim, J. W., \& Zakrajšek, E. (2014). Uncertainty, Financial Frictions, and Investment Dynamics. National Bureau of Economic Research, Working Paper, 20038. http://dx.doi.org/10.3386/w20038

Gupta, R., Lau, C. K. M., Nel, J. A., \& Sheng, X. (2020). Monetary policy uncertainty spillovers in time and frequency domains. Journal of Economic Structures, 9(41), 41. http://dx.doi.org/10.1186/s40008-020-00219-z

Gupta, R., Ma, J., Risse, M., \& Wohar, M. E. (2018). Common Business Cycles and Volatilities in US States and MSAs: The Role of Economic Uncertainty. Journal of Macroeconomics, 57, 317-337. http://dx.doi.org/10.1016/j.jmacro.2018.06.009

Hansen, B. (1997). Inference in TAR Models. Studies in Nonlinear Dynamics and Econometrics, 2(1), 1-16. http://dx.doi.org/10.2202/1558-3708.1024 
Hosoya, Y. (1991). The decomposition and measurement of the interdependency between second-order stationary processes. Probability Theory and Related Fields, 88(4), 429-444. http://dx.doi.org/10.1007/BF01192551

IMF. (2013). 2013 Spillover Report - Analytical Underpinnings and Other Background 2013(60).

Jones, P. M., \& Olson, E. (2015). The International Effects of US Uncertainty. International Journal of Finance \& Economics, 20, 242-252. http://dx.doi.org/10.1002/ijfe.1513

Kabundi, A., Loate, T., \& Viegi, N. (2020). Spillovers of the Conventional and Unconventional Monetary Policy from the US to South Africa. Economic Research Southern Africa, ERSA Working Paper, 818.

Kalu, E., Okoyeuzu, C., Ukemenam, A., \& Ujunwa, A. (2020). Spillover effects of the US monetary policy normalization on African stock markets. Journal of Economic Development, 22(1), 3-19. http://dx.doi.org/10.1108/JED-09-2019-0038

Kang, W., Ratti, R. A., \& Vespignani, J. (2019). Impact of Global Uncertainty on the Global Economy and Large Developed and Developing Economies. Applied Economics, 52(22), 2392-2407. http://dx.doi.org/10.1080/00036846.2019.1690629

Li, R., Li, S., Yuan, D., \& Yu, K. (2020). Does economic policy uncertainty in the U.S. influence stock markets in China and India? Time-frequency evidence. Applied Economics, 52, 4300-4316. http://dx.doi.org/10.1080/00036846.2020.1734182

Mensi, W., Hammoudeh, S., Reboredo, J. C., \& Nguyen, D. K. (2014). Do Global Factors Impact BRICS Stock Markets? A Quantile Regression Approach. Emerging Markets Review, 19, 1-17. http://dx.doi.org/10.1016/j.ememar.2014.04.002

Olanipekun, I. O., Gungor, H., \& Olasehinde-Williams, G. (2019). Unraveling the Causal Relationship between Economic Policy Uncertainty and Exchange Market Pressure in BRIC Countries: Evidence from Bootstrap Panel Granger Causality. SAGE Open, 9(2). http://dx.doi.org/10.1177/2158244019853903

Perron, P. (1990). Testing for a unit root in a time series with a changing mean. Journal of Business \& Economic Statistics, 8(2), 153-162. http://dx.doi.org/10.2307/1391977

PolicyUncertainty. (2020). Retrieved from http://www.policyuncertainty.com/

Sum, V. (2012). The Reaction of Stock Markets in the BRIC Countries to Economic Policy Uncertainty in the United States. SSRN. http://dx.doi.org/10.2139/ssrn.2094697

Sum, V. (2013). The ASEAN stock market performance and economic policy uncertainty in the United States. Economic Papers, 32(4), 512-521. http://dx.doi.org/10.1111/1759-3441.12049

Zhang, D., Lei, L., Ji, Q., \& Kutan, A. M. (2019). Economic Policy Uncertainty in the US and China and Their Impact on the Global Markets. Economic Modelling, 79, 47-56. http://dx.doi.org/10.1016/j.econmod.2018.09.028

Zivot, E., \& Andrews, D. W. K. (2002). Further evidence on the great crash, the oil-price shock, and the unit-root hypothesis. Journal of Business \& Economic Statistics, 20(1), 25-44. http://dx.doi.org/10.1198/073500102753410372

\section{Copyright}

This article is an open access article distributed under the terms and conditions of the Creative Commons Attribution-NonCommercial-NoDerivatives 4.0 International License. 